\title{
Short communication: Lymphocyte proliferative responses in cattle naturally infected with digital dermatitis consist of CD8+ and $y \delta-T$ cells but lack CD4+ T cells
}

\author{
Jennifer H. Wilson-Welder, ${ }^{* 1}$ Jarlath E. Nally, ${ }^{*}$ David P. Alt, ${ }^{*}$ Samuel B. Humphrey, $†$ and Steven C. Olsen* \\ *Infectious Bacterial Diseases, and \\ †Microscopy Services, National Animal Disease Center, Agriculture Research Service, USDA, Ames, IA 50010
}

\begin{abstract}
Digital dermatitis is an infectious disease of cattle and the leading cause of lameness. This disease is complicated by the reoccurrence of the lesions and the observation of lesions on more than one limb at different time points, indicating infection may not result in a protective immune response. The objective of this study was to characterize the peripheral blood cellular response in naturally infected and naïve cattle to bacterial antigens derived from pathogens associated with digital dermatitis lesions. Peripheral blood mononuclear cells were isolated from dairy cattle identified as having active or chronic lesions during routine hooftrimming. Following bacterial antigen stimulation, cells were analyzed for proliferation and phenotype by flow cytometry, and culture supernatants were analyzed for IFN- $\gamma$ secretion. Digital-dermatitis-infected animals had greater serum antibody titers to treponemal antigens, higher percentages of proliferating CD8+, $\gamma \delta-\mathrm{T}$ cells, and B cells, and increased IFN- $\gamma$ secretion in vitro when compared with responses of naïve animals. No increase in proliferation of CD4 $+\mathrm{T}$ cells was detected in infected or naïve cattle. Although CD $8+$ and $\gamma \delta$-T cell responses may be antigen specific, the memory nature or long-lived response is yet unknown. The lack of responsiveness of CD4+ memory cells to treponemal antigens could explain the high rate of reoccurrence of digital dermatitis in infected animals.
\end{abstract}

Key words: digital dermatitis, cellular immunity, flow cytometry

\section{Short Communication}

Digital dermatitis (DD) is a leading cause of lameness in cattle worldwide and a significant cause of economic losses through decreased production, premature

Received September 28, 2017

Accepted May 2, 2018.

${ }^{1}$ Corresponding author: Jennifer.wilson-welder@ars.usda.gov culling, and cost of treatment/prevention. The disease can also affect welfare and well-being of food-producing animals (Losinger, 2006). Digital dermatitis is a polymicrobial infection causing ulcerative proliferative lesions between the digits, in the pastern area, and rarely, elsewhere on the leg and udder (Clegg et al., 2016). Although spirochetes from the genus Treponema are dominant isolates from lesions, other anaerobic and aerobic bacteria are present (Wilson-Welder et al., 2015). Lesions are hyperkeratinized, proliferative, necrotic, or ulcerative, may be painful to touch, and generally bleed easily (Plummer and Krull, 2017). An important contributor to the economic impact of DD is the chronicity of lesions and the frequency for recrudescence of lesions in previously affected animals. Affected animals develop a robust antibody response to Treponema antigens and to other bacteria thought to be involved in the lesions (Elliott and Alt, 2009; Moe et al., 2010). Trott et al. (2003) demonstrated a brief proliferative response by peripheral blood mononuclear cells (PBMC) to Treponema phagedenis antigens that declined with convalescence (Trott et al., 2003). Within lesions, small lymphocytes are occasionally observed, but their roles have not been characterized. The goal of this investigation was to characterize the cellular immune response [cluster of differentiation (CD) 4+, $\mathrm{CD} 8+$, gamma-delta $\mathrm{T}$ cell receptor $(\boldsymbol{\gamma} \boldsymbol{\delta}-\mathbf{T C R}+)$, or $\mathrm{B}$ cell +$]$ in cattle with previously diagnosed DD lesions and determine if activation of immunologic memory responses (i.e., $\mathrm{CD} 4+$ or $\mathrm{CD} 8+\mathrm{T}$ cells) occurs. We hypothesized that there is a failure to generate immunological memory of one or more cell types, which may contribute to reoccurrence of DD lesions in some cattle.

Holstein dairy cattle $(\mathrm{n}=6), 2$ to 5 yr of age and lactating, were housed in production dairy-like facilities at the National Animal Disease Center (NADC), Ames, Iowa, and identified as having probable DD lesions. Lesions were observed during routine hoof-trimming and resulted from natural exposure (Supplemental Figure S1; https://doi.org/10.3168/jds.2017-13913). Negative control cattle $(\mathrm{n}=3)$ were Holstein-Angus crossbred 
female cattle, 4 yr of age, and were housed in a separate outdoor facility at NADC. Control animals had no lesions or exposure to animals with DD lesions during the 4 yr they had been at NADC. Visual inspection at postmortem indicated no scars or other signs of DD; however, no histology was performed to confirm this. Sample size was dictated by available animals on site that met definitions for infected and negative control groups. Presented data are the average of 2 independent samplings obtained at 4 and 5 wk after lesion identification in infected animals. All animal procedures were approved by National Animal Disease Center Institutional Animal Care and Use Committee (Animal Use Protocol Numbers ARS-2797, 2763, 2819, 2797, and 2500) in accordance with the standards established by the Animal Welfare Act (USDA, 2017) and the Guide for the Care and Use of Agricultural Animals in Research and Teaching (FASS, 2010).

Treponema phagedenis, strains $4 \mathrm{~A}$ and 5B, Treponema denticola [strain: CIP 103919, ATCC \#35405, American Type Culture Collection (ATCC), Manassas, VA], Treponema vincentii (strain: Smibert, ATCC \#35580), and Treponema pedis (strain T3552B; DSMZ culture \#18691, Leibinz-Institut DSMZ-Deutsche Sammlung von Mikroorganismen und Zellkulturen $\mathrm{GmbH}$, Braunschweig, Germany) were grown in Oral Treponeme Enrichment Broth (OTEB, Anaerobe Systems, Morgan Hill, CA) to confluence, harvested and washed by centrifugation, and antigen prepared from whole-cell sonicates as described previously (Jergens et al., 2007; Wilson-Welder et al., 2013). Briefly, after washing by centrifugation, cells were suspended in minimal amount of sterile distilled water, frozen at $-80^{\circ} \mathrm{C}$ overnight, and lyophilized (FreeZone 2.5, Labconco, Kansas City, $\mathrm{MO}$ ). Dried powdered cells were stored at $-20^{\circ} \mathrm{C}$ until used to create $10 \mathrm{mg} / \mathrm{mL}$ suspensions in sterile PBS (pH 7.4). Rehydrated suspensions were sonicated for 1 min in 15-s pulsed bursts while stored on ice. Sonicated solutions were sterilized using a UV-Stratalinker, aliquoted, and stored at $-20^{\circ} \mathrm{C}$ until use.

Blood was collected 4 wk following hoof-trimmer visit via jugular venipuncture. Serum was separated by centrifugation and stored at $-20^{\circ} \mathrm{C}$. Whole cell sonicates of Treponema antigens $(10-20 \mu \mathrm{g} / \mathrm{mL}$ in PBS) were bound overnight to wells in 96-well plates (Nunc Maxisorp, Thermo Fisher, Rochester, NY). Serum was diluted 1:50 and serially diluted by factor of 2 and 100 $\mu \mathrm{L}$ added to individual wells, and incubated at $37^{\circ} \mathrm{C}$ for $1 \mathrm{~h}$ and $4^{\circ} \mathrm{C}$ overnight. After 3 washes with PBS containing $0.05 \%$ (vol/vol) Tween 20 (Sigma, St. Louis, $\mathrm{MO}), 100 \mu \mathrm{L}$ of $1: 1,000$ dilution horseradish peroxidase-conjugated sheep anti-bovine IgG $(\gamma$-chain; KPL, Gaithersburg, MD) was added and plates incubated for $1 \mathrm{~h}$ at $37^{\circ} \mathrm{C}$. Plates were washed 5 times with PBS-
Tween, and $100 \mu \mathrm{L}$ of 1-step SureBlue Reserve TMB Microwell Peroxidase Substrate (KPL) was added to all wells and the reaction stopped using $100 \mu \mathrm{L}$ of TMB SureBlue Stop Solution (R \& D systems, Minneapolis, $\mathrm{MN}$ ). Plates were read on a microtiter plate reader at $650 \mathrm{~nm}$. The ELISA data for each animal are reported as the lowest dilution of serum with an optical density that was greater than 2 standard deviations above the optical density mean for wells containing PBS only. The assay was performed in duplicate with samples blinded. The ELISA data were log-transformed and analyzed using a 2-way ANOVA with repeated measures and means separated by Tukey's multiple comparison test (GraphPad Prism 7, GraphPad Software Inc., La Jolla, CA).

Blood was collected by jugular vein into $10 \mathrm{~mL}$ of $2 \times$ Acid-Dextran-Citrate purified on a density gradient (Histopaque, density 1077, Sigma). Isolated PBMC (5 $\times 10^{6}$ cells) were labeled with $10 \mathrm{n} M$ Cell Trace Violet (Invitrogen, Carlsbad, CA) and incubated in duplicate to wells of a 96-well microtiter plate containing 25 $\mu \mathrm{g} / \mathrm{mL}$ of bacterial whole cell sonicates, $10 \mu \mathrm{g} / \mathrm{mL}$ of pokeweed mitogen or medium alone (no stimulation) in RPMI 1640 (Life Technologies, Carlsbad, CA) supplemented with $10 \%$ fetal calf serum, $2 \mathrm{mM}$ L-glutamine, 1\% Pen-Strep (10,000 U/mL, Gibco, Waltham, MA), 25 $\mathrm{m} M$ HEPES buffer, $1 \%$ NEAA, $1 \%$ EAA, $1 \%$ sodium pyruvate, $50 \mu M 2$ - $\beta$-mercaptoethanol, and $100 \mu \mathrm{g} / \mathrm{mL}$ of gentamicin sulfate with sodium bicarbonate solution added to restore the $\mathrm{pH}$ to approximately 7 . Plates were incubated at $37^{\circ} \mathrm{C}, 5 \% \mathrm{CO}_{2}$ for $5 \mathrm{~d}$. A duplicate plate was inoculated with unlabeled cells from which $150 \mu \mathrm{L}$ of cell culture supernatants were collected at 48 $\mathrm{h}$ after stimulation. Supernatants were frozen at $-20^{\circ} \mathrm{C}$ until assayed for cytokine concentrations.

After $5 \mathrm{~d}$ culture, labeled PBMC were harvested by centrifugation and labeled with live/dead discriminator dye (Zombie Yellow, BioLegend, San Diego, CA), then labeled with antibodies to cell surface markers for CD4, CD8, $\gamma \delta$-TCR, and B cells. Primary antibodies, secondary antibodies, dilutions, and suppliers are given in Supplemental Table S1 (https://doi.org/10.3168/jds .2017-13913). After labeling with secondary antibodies cells were then fixed and analyzed on a BD LSRII Flow cytometer and data analyzed using FlowJo software with a minimum of 2,000 cells within the live gate required for analysis. Lymphocyte populations were plotted against fluorescent intensity of each antibody using: CD4 versus B cell markers and CD8 versus $\gamma \delta$-TCR with fluorescence-minus-one for gate restrictions similar to previously published reports (Krueger et al., 2016). The percentage of each identified subset was analyzed for decrease in fluorescence intensity of cell membrane proliferation dye as compared with background or no 
stimulation wells. Data were further analyzed using GraphPad Prism 7 software fitting 2 way-ANOVA with Sidak's multiple comparisons post-test, comparing within groups (negative or DD+) the effect of well stimulation as compared with background or no stimulation wells and Dunnett's multiple comparisons posttest for within well stimulation between groups with groups being the cattle DD status (DD+, negative) and treatments being well stimulation (bacterial antigen, \pm controls). Means were significant if $P \leq 0.05$.

Concentrations of IFN $\gamma$ in cell culture supernatants collected at $48 \mathrm{~h}$ post-stimulation were determined using an AlphaLisa kit (PerkinElmer) following the manufacturer's suggested protocol. Data were analyzed using a 2-way ANOVA with Sidak's multiple comparisons post-test for comparing within group effect of well stimulation as compared with no stimulation wells and Dunnett's multiple comparisons for comparison between treatment groups (DD+ vs. negative) and between bacterial antigens. Means were significant if $P \leq 0.05$.

Serum antibody, cellular proliferation, and cellular secretion of IFN $\gamma$ was measured in response to 4 Treponema species and 5 strains associated with DD. No significant difference was observed in responses of infected or negative cattle; thus, data from individual Treponema species and strains are presented as one group.

In the current study, cattle with DD lesions had greater $(P<0.0001)$ antibody responses to Treponema antigens, regardless of Treponema strain when compared with control cattle (Figure 1). This increase in response to treponemal antigens was also reflected in total PBMC proliferation (Figure 2A). Examining the phenotypes of cells proliferating in response to treponemal antigens, there was no difference between $\mathrm{DD}+$ and negative groups in percentages of CD4+ cells (Figure 2B). However, there was a small but significant difference $(P=0.003)$ in percentage of proliferating CD8+ cells (Figure 2C). The CD8+ population did not include CD8 $+\gamma \delta$-TCR + cells. Significant differences between negative and $\mathrm{DD}+$ groups were observed in percentage of proliferating $\gamma \delta$-TCR + cells (Figure 2D) and percentage of proliferating $\mathrm{B}$ cells (Figure $2 \mathrm{E}$ ). No differences was observed $(P>0.05)$ between negative and $\mathrm{DD}+$ cattle in proliferation of unstimulated cells or cells stimulated with mitogen (data not shown). After stimulation for $48 \mathrm{~h}$ with Treponema antigens, wells with PBMC from DD+ animals had greater $(P<0.05)$ concentrations of IFN $\gamma$ in supernatants when compared with responses from negative animals (Figure 3).

The objective of this study was to characterize cellular responses in cattle naturally infected with DD. Others have demonstrated that cattle with DD have robust antibody responses to treponemal antigens and other types of bacteria within lesions (Walker et al., 1997; Demirkan et al., 1999; Trott et al., 2003; Elliott and Alt, 2009; Vink et al., 2009; Moe et al., 2010). Therefore, it was not surprising that we observed B cells from cattle with DD lesions proliferated in response to Treponema antigens in significantly greater percentages than from naive cattle. Whole cell sonicate preparations may contain crosslinking antigens that can induce proliferation of cells and secretion of antibody in the absence of any T cell help (Murphy et al., 2008). Elliot and Alt (2009) indicated that antibody to T. phagedenis antigens was biased toward IgG subclass 1 , indicating a T-helper type- 2 response; however, presence of large amounts of IgG subclass 3, a subclass typically generated by short-lived memory B cells to polysaccharide and LPS-like antigens in T-independent pathways, could not be ruled out (Elliott and Alt, 2009). Regardless, others have observed that antibody responses fade quickly after lesion resolution and anecdotal evidence from producers would seem to indicate that an antibody response does not help resolve lesions or protect from reinfection (Walker et al., 1997; Trott et al., 2003; Gomez et al., 2014).

We observed that $\gamma \delta$-T cells of cattle with DD proliferate in response to stimulation with bacterial antigens. Other investigations report antigen-specific $\gamma \delta$-T cells proliferating and producing IFN $\gamma$ isolated vaccinated or experimentally infected animals to other pathogens (Naiman et al., 2001; Krueger et al., 2016). Bovine $\gamma \delta$-T cells have been described as innate-like immune cells with the ability to recognize diverse ligands including some pathogen-associated molecular patterns

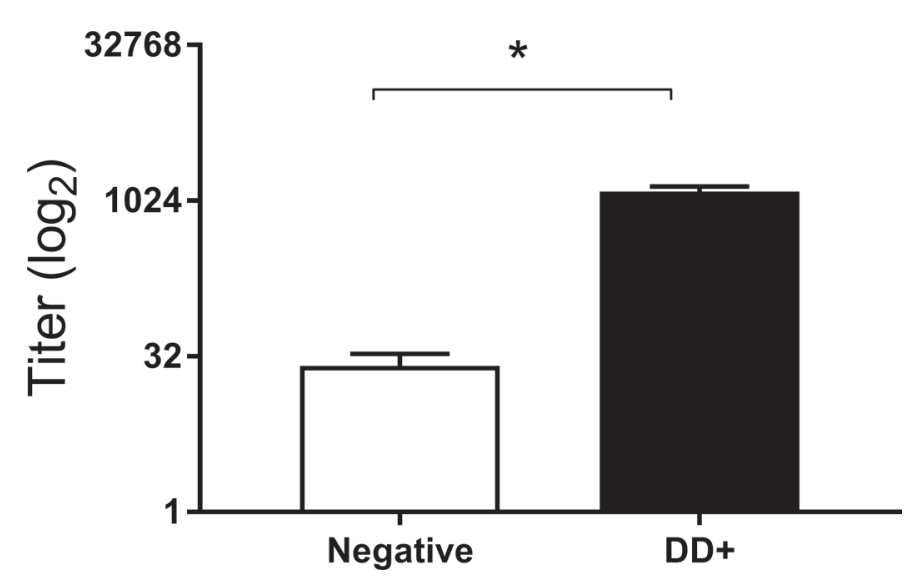

Figure 1. Serum antibody titers to treponemal antigen as measured by dilution ELISA. Control animals (negative) were never exposed to digital dermatitis; $\mathrm{DD}+$ are animals with digital dermatitis lesions observed during routine foot-trimming $4 \mathrm{wk}$ before blood collection. Group means and SEM are shown. * indicates a statistically significant difference $(P<0.0001)$ between negative and DD+. 
A

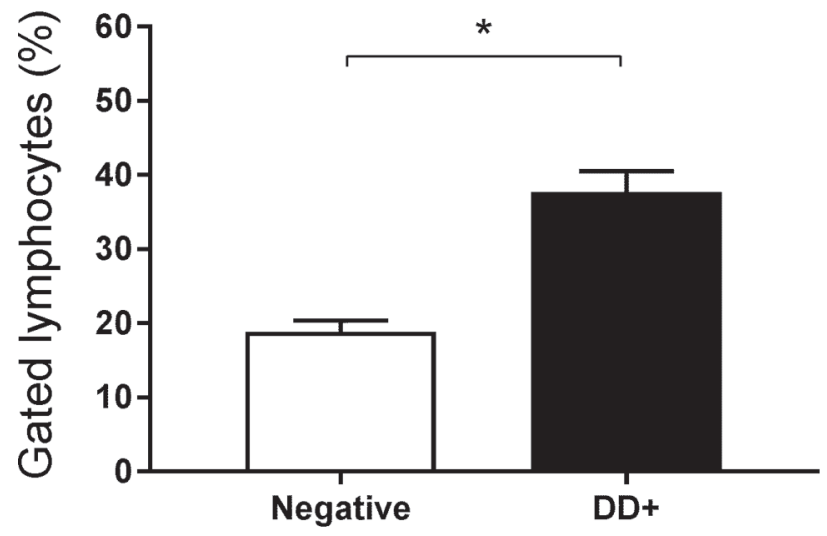

C
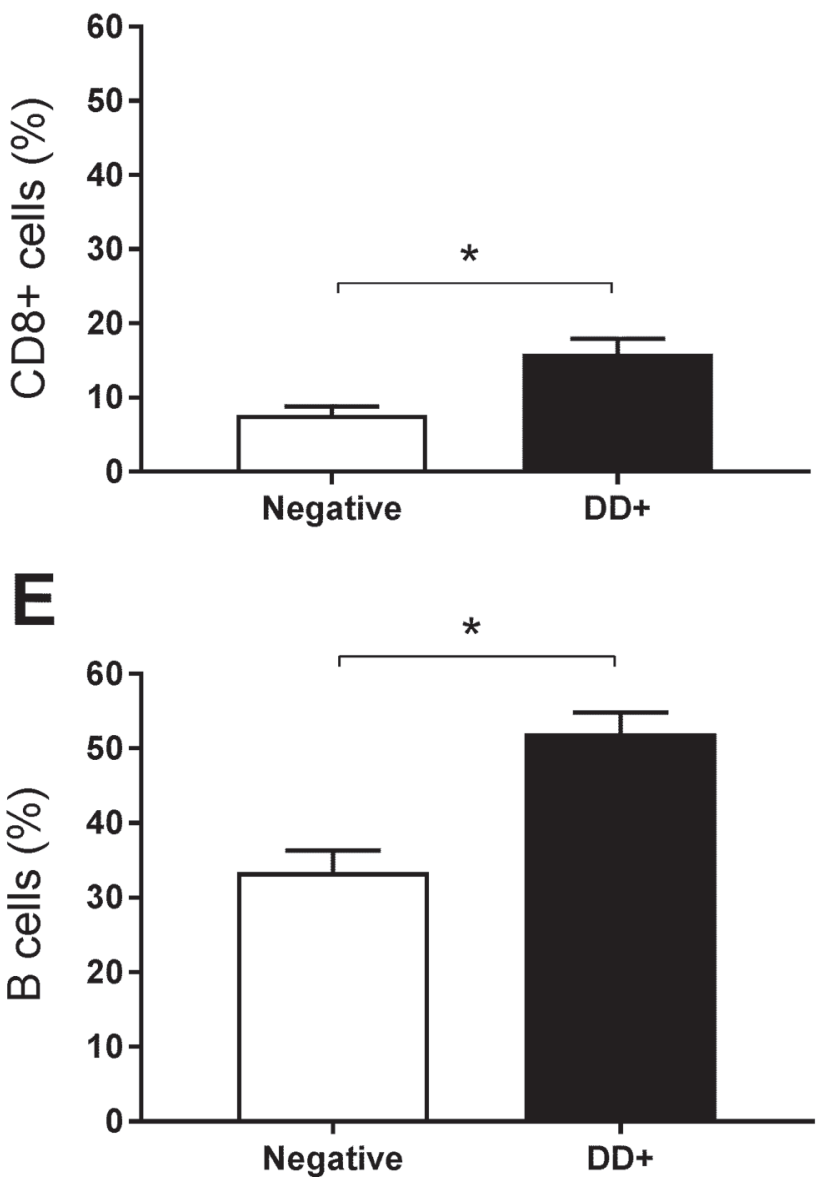

B

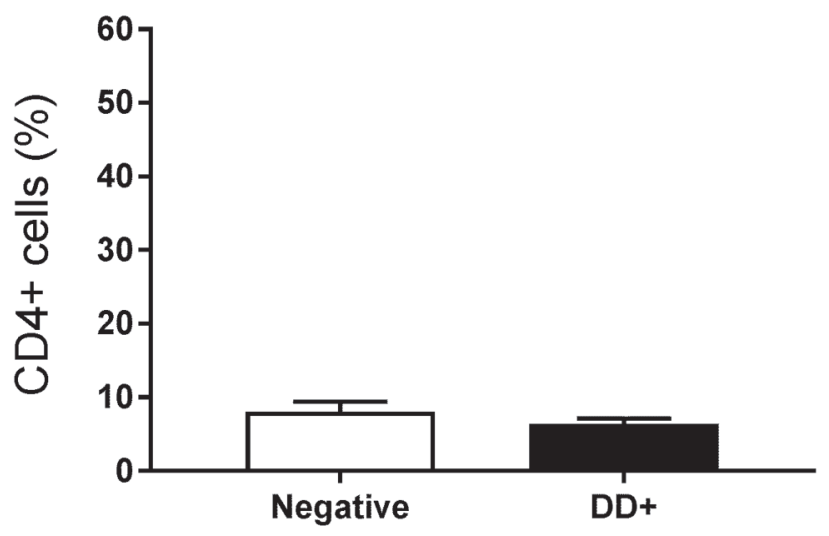

$\mathbf{D}$

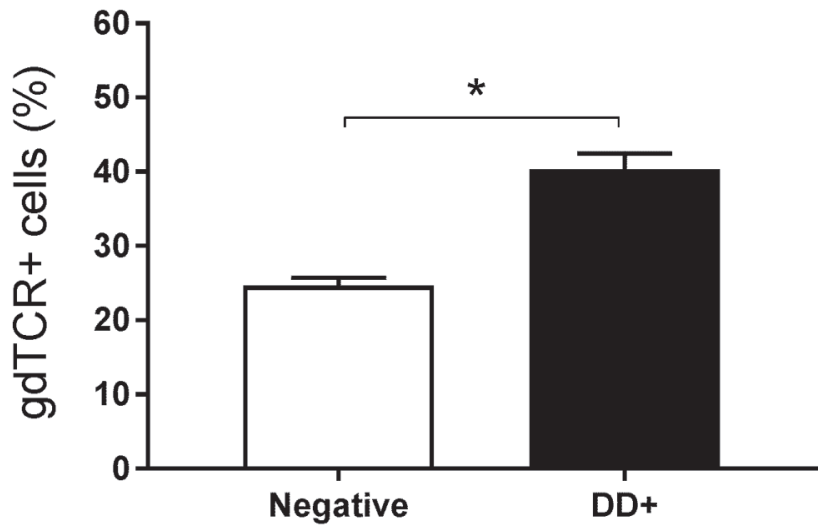

Figure 2. Proliferative responses and cellular phenotypes of peripheral blood mononuclear cells isolated from the blood of cattle negative (no exposure) to digital dermatitis or with lesions detected during routine foot-trimming 4 wk before blood collection (DD+). Peripheral blood mononuclear cells were stimulated for $5 \mathrm{~d}$ with treponemal antigens. Group mean and SEM shown. * indicates a statistically significant difference between negative and DD + groups. (A) Percentage of proliferating total lymphocytes, $P=0.0004$. (B) Percentage of proliferating cluster of differentiation (CD) $4+$ cells, no significant difference. (C) Percentage of proliferating CD8+ cells, $P=0.0003$. (D) Percentage of proliferating cells expressing $\gamma \delta$-T cell receptor (gdTCR +$), P<0.0001$. (E) Percentage of cells expressing surface IgM (B cells), $P<0.0001$. 
(Hein and Dudler, 1997; Guzman et al., 2014). The highly diverse receptor repertoire of bovine $\gamma \delta$-T cells is one of many differences between ruminants, mice, and humans, along with the relatively high numbers of these cells in ruminant tissues, including the skin and peripheral blood circulation (Guzman et al., 2014). The WC1 receptor on bovine $\gamma \delta$-T cells appears to have affinity for protein and nonprotein antigens from Leptospira and Mycobacteria, indicating a possible role in detecting bacterial antigens in non-MHC presentation (Baldwin et al., 2014). In this limited study, the role of $\mathrm{WC} 1+$ specificity to Treponema antigens was not investigated. Much like CD4+ or CD8 $+\mathrm{T}$ cells, $\gamma \delta$-T cells can have memory-like phenotypes, proliferating and releasing IFN $\gamma$ upon recognition of their cognizant antigen. Interferon $\gamma$, a potent pro-inflammatory cytokine, has multiple functions activating cells of innate and adaptive immunity for long-lived memory and pathogen clearance, and is generally associated with T-helper type 1 responses (Murphy et al., 2008). We observed increase in IFN $\gamma$ release from stimulated cells from cattle with DD over DD-negative cattle; however, more study is needed to discern the phenotype of cells secreting IFN $\gamma$.

Additionally, we observed an increase in CD8+ cell proliferation in antigen stimulated cells from cattle with DD lesions over DD-negative cattle. The CD8+ memory cells are linked to many dermal inflammatory conditions, such as atopic dermatitis, experimentally induced psoriasis, and viral infections (Gunderson et

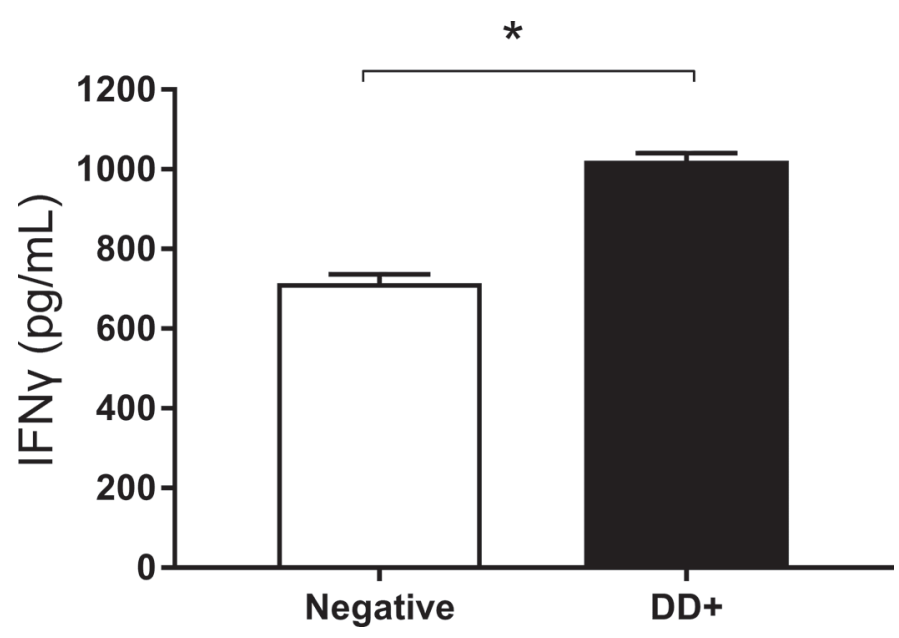

Figure 3. Interferon $\gamma$ cytokine release from peripheral blood mononuclear cells isolated from negative (no exposure) cattle or cattle with digital dermatitis lesions detected during routine foot-trimming 4 wk before blood collection (DD + ). Peripheral blood mononuclear cells were stimulated for $48 \mathrm{~h}$ with treponemal antigen lesions before supernatants were collected. Group mean and SEM shown. * indicates a statistically significant difference between negative and $\mathrm{DD}+, \mathrm{P}<$ 0.0001 . al., 2013; Hijnen et al., 2013; Carbone and Gebhardt, 2014). Usually localized in tissues, these resident memory cells actively promote lymphocyte recruitment to the site of infection/inflammation, are capable of Th1/ Th2 cytokine biases typically associated with CD4+ T cells. Additional study is be needed to determine if the proliferating CD8+ cells observed from cattle with DD lesions are resident memory cells, expressing markers of memory cells such as CD45RO and skin-specific homing signals such as CCR8 (Denis et al., 2011; McCully et al., 2012).

Alternatively, the proliferating CD8+ cells observed could also be NK-like or NK-T cells. The NK-T cells in ruminants are capable of responding specifically to bacterial antigens in recall reactions, including proliferation and the production of IFN $\gamma$ (Hope et al., 2002; Zuerner et al., 2007; Park et al., 2015). Like $\gamma \delta$-T cells, NKT cells may respond to lipid antigens presented by CD1 rather than MHC (Hope et al., 2002). The NKT cells can comprise a significant proportion of $\mathrm{CD} 8+$ fraction in ruminants, and as in this study can be easily overlooked by utilizing too few cellular markers to fully identify cellular populations (Park et al., 2015).

Of particular note is the lack of proliferation in the CD4+ cell population. The cell type most often associated with helper $\mathrm{T}$ cell functions (i.e., cytokine secretion for $\mathrm{B}$ cell class switching, cytotoxic $\mathrm{T}$ cell activation, and macrophage activation) and long-lived memory cell responses (Murphy et al., 2008). It is unclear how long-lived memory $\gamma \delta$, NKT, or CD $8+\mathrm{T}$ cell responses may be, or how the lack of CD4+ responses affect the effector functions of the cellular responses. The time point of several weeks after the hoof-trimmer visit was deliberately chosen to allow for any immune responses created in a new acute lesion to develop fully. As with the antibody response, it would appear that the cellular response induced by natural exposure or infection is not protective, and being slightly inflammatory (Th1 bias, increase in IFN $\gamma$ ), may contribute to lesion development.

It is not in the pathogen's best interest to generate immune responses that facilitate pathogen clearance, tissue healing, or other means of the pathogen's destruction or limitation to metabolites. The use of different adjuvants, immune modulators, or inoculation methodology can tweak the immune response into eliciting a differently biased immune response to that same pathogen (Sallusto et al., 2010). Heifers may be exposed to DD before they ever enter the milking herd; thus, vaccination is likely to occur in the face of preexisting immune response (Gomez et al., 2015). It is critical to understand the pre-existing immune response to $\mathrm{DD}$, even if it is not effective, so that vaccines can be generated that not only create the right type of im- 
mune response (e.g., humoral, cellular, Th1, Th17, and so on) but can do so with pre-existing responses.

Further study is needed to follow greater numbers of cattle for longer periods of time, including examining cellular responses in acute versus chronic and fully healed lesions over time. The limitations of this study show the need to take full advantage of the ever-expanding immunological toolbox available for bovines to conduct complex analysis into cellular phenotype and function.

In conclusion, we observed an antigen-specific proliferative response in cattle with DD lesions consisting of B cells, CD $8+$, and $\gamma \delta$-TCR $+\mathrm{T}$ cells. Further studies are needed to elucidate the further phenotype and memory properties of these cells. The immune response elicited by natural infection consisting mostly of antibody, CD8+, and $\gamma \delta$-T cells is not effective at overcoming existing immune responses, effective or not, has implications for vaccine design.

\section{ACKNOWLEDGMENTS}

The authors report no conflicts of interest. Work was completed by US Department of Agriculture employees in the course of their assigned duties in relation to project number 5030-32000-107-00-D. Mention of trade names or commercial products in this study is solely for providing specific information and does not imply recommendation or endorsement by the USDA. USDA is an equal opportunity provider and employer. The authors acknowledge Ami Frank and Lilia Walther (Infectious Bacterial Disease, NADC, Ames, IA) for excellence in laboratory assistance, Duane Zimmerman (Ruminant Disease and Immunology, NADC, Ames, IA) for assistance in obtaining the samples, and the National Centers for Animal Health (Ames, IA) Animal Resource Unit animal care staff for excellence in animal care.

\section{REFERENCES}

Baldwin, C. L., H. Hsu, C. Chen, M. Palmer, J. McGill, W. R. Waters, and J. C. Telfer. 2014. The role of bovine gammadelta T cells and their $\mathrm{WC} 1$ co-receptor in response to bacterial pathogens and promoting vaccine efficacy: A model for cattle and humans. Vet. Immunol. Immunopathol. 159:144-155.

Carbone, F. R., and T. Gebhardt. 2014. Immunology. A neighborhood watch upholds local immune protection. Science 346:40-41.

Clegg, S. R., S. D. Carter, J. P. Stewart, D. M. Amin, R. W. Blowey, and N. J. Evans. 2016. Bovine ischaemic teat necrosis: A further potential role for digital dermatitis treponemes. Vet. Rec. 178:71.

Demirkan, I., R. L. Walker, R. D. Murray, R. W. Blowey, and S. D. Carter. 1999. Serological evidence of spirochaetal infections associated with digital dermatitis in dairy cattle. Vet. J. 157:69-77.

Denis, M., S. J. Lacy-Hulbert, B. M. Buddle, J. H. Williamson, and D. N. Wedlock. 2011. Streptococcus uberis-specific T cells are present in mammary gland secretions of cows and can be activated to kill S. uberis. Vet. Res. Commun. 35:145-156.
Elliott, M. K., and D. P. Alt. 2009. Bovine immune response to papillomatous digital dermatitis (PDD)-associated spirochetes is skewed in isolate reactivity and subclass elicitation. Vet. Immunol. Immunopathol. 130:256-261.

FASS. 2010. Guide for the Care and Use of Agricultural Animals in Research and Teaching. FASS, Champaign, IL.

Gomez, A., K. S. Anklam, N. B. Cook, J. Rieman, K. A. Dunbar, K. E. Cooley, M. T. Socha, and D. Dopfer. 2014. Immune response against Treponema spp. and ELISA detection of digital dermatitis. J. Dairy Sci. 97:4864-4875.

Gomez, A., N. B. Cook, M. T. Socha, and D. Dopfer. 2015. Firstlactation performance in cows affected by digital dermatitis during the rearing period. J. Dairy Sci. 98:4487-4498.

Gunderson, A. J., J. Mohammed, F. J. Horvath, M. A. Podolsky, C. R. Anderson, and A. B. Glick. 2013. CD8 (+) T cells mediate RASinduced psoriasis-like skin inflammation through IFN-gamma. J. Invest. Dermatol. 133:955-963.

Guzman, E., J. Hope, G. Taylor, A. L. Smith, C. Cubillos-Zapata and B. Charleston. 2014. Bovine gammadelta T cells are a major regulatory T cell subset. J. Immunol. 193:208-222.

Hein, W. R., and L. Dudler. 1997. TCR gamma delta+ cells are prominent in normal bovine skin and express a diverse repertoire of antigen receptors. Immunology 91:58-64.

Hijnen, D., E. F. Knol, Y. Y. Gent, B. Giovannone, S. J. Beijn, T. S. Kupper, C. A. Bruijnzeel-Koomen, and R. A. Clark. 2013. CD8(+) $\mathrm{T}$ cells in the lesional skin of atopic dermatitis and psoriasis patients are an important source of IFN-gamma, IL-13, IL-17, and IL-22. J. Invest. Dermatol. 133:973-979.

Hope, J. C., P. Sopp, and C. J. Howard. 2002. NK-like CD8(+) cells in immunologically naive neonatal calves that respond to dendritic cells infected with Mycobacterium bovis BCG. J. Leukoc. Biol. 71:184-194.

Jergens, A. E., J. H. Wilson-Welder, A. Dorn, A. Henderson, Z. Liu, R. B. Evans, J. Hostetter, and M. J. Wannemuehler. 2007. Helicobacter bilis triggers persistent immune reactivity to antigens derived from the commensal bacteria in gnotobiotic $\mathrm{C} 3 \mathrm{H} / \mathrm{HeN}$ mice. Gut 56:934-940.

Krueger, L. A., D. C. Beitz, S. B. Humphrey, and J. R. Stabel. 2016. Gamma delta T cells are early responders to Mycobacterium avium ssp. paratuberculosis in colostrum-replete Holstein calves. J. Dairy Sci. 99:9040-9050

Losinger, W. C. 2006. Economic impacts of reduced milk production associated with papillomatous digital dermatitis in dairy cows in the USA. J. Dairy Res. 73:244-256.

McCully, M. L., K. Ladell, S. Hakobyan, R. E. Mansel, D. A. Price, and B. Moser. 2012. Epidermis instructs skin homing receptor expression in human T cells. Blood 120:4591-4598.

Moe, K. K., T. Yano, K. Misumi, C. Kubota, K. Nibe, W. Yamazaki, M. Muguruma, and N. Misawa. 2010. Detection of antibodies against Fusobacterium necrophorum and Porphyromonas levii-like species in dairy cattle with papillomatous digital dermatitis. Microbiol. Immunol. 54:338-346.

Murphy, K., P. Travers, and M. Walport. 2008. Janeway's Immunobiology. 7th ed. Garland Science, Taylor \& Francis Group, New York, NY

Naiman, B. M., D. Alt, C. A. Bolin, R. Zuerner, and C. L. Baldwin 2001. Protective killed Leptospira borgpetersenii vaccine induces potent Th1 immunity comprising responses by CD4 and gammadelta T lymphocytes. Infect. Immun. 69:7550-7558.

Park, K. T., K. S. Seo, N. A. Godwin, B. J. Van Wie, M. Y. Gulbahar, Y. H. Park, and W. C. Davis. 2015. Characterization and expression of monoclonal antibody-defined molecules on resting and activated bovine alphabeta, gammadelta $\mathrm{T}$ and NK cells. Vet. Immunol. Immunopathol. 168:118-130.

Plummer, P. J., and A. Krull. 2017. Clinical perspectives of digita dermatitis in dairy and beef cattle. Vet. Clin. North Am. Food Anim. Pract. 33:165-181.

Sallusto, F., A. Lanzavecchia, K. Araki, and R. Ahmed. 2010. From vaccines to memory and back. Immunity 33:451-463.

Trott, D. J., M. R. Moeller, R. L. Zuerner, J. P. Goff, W. R. Waters, D. P. Alt, R. L. Walker, and M. J. Wannemuehler. 2003. Charac- 
terization of Treponema phagedenis-like spirochetes isolated from papillomatous digital dermatitis lesions in dairy cattle. J. Clin. Microbiol. 41:2522-2529.

USDA. 2017. Animal Welfare Act and Animal Welfare Regulations. USDA, Washington, DC. Accessed Jun. 1, 2018. https://www .aphis.usda.gov/animal_welfare/downloads/AC_BlueBook_AWA _FINAL_2017_508comp.pdf.

Vink, W. D., G. Jones, W. O. Johnson, J. Brown, I. Demirkan, S. D. Carter, and N. P. French. 2009. Diagnostic assessment without cut-offs: application of serology for the modelling of bovine digital dermatitis infection. Prev. Vet. Med. 92:235-248.

Walker, R. L., D. H. Read, K. J. Loretz, D. W. Hird, and S. L. Berry. 1997. Humoral response of dairy cattle to spirochetes isolated from papillomatous digital dermatitis lesions. Am. J. Vet. Res. 58:744-748.

Wilson-Welder, J. H., D. P. Alt, and J. E. Nally. 2015. Digital dermatitis in cattle: Current bacterial and immunological findings. Animals (Basel) 5:1114-1135.

Wilson-Welder, J. H., M. K. Elliott, R. L. Zuerner, D. O. Bayles, D. P. Alt, and T. B. Stanton. 2013. Biochemical and molecular characterization of Treponema phagedenis-like spirochetes isolated from a bovine digital dermatitis lesion. BMC Microbiol. 13:280.

Zuerner, R. L., M. Heidari, M. K. Elliott, D. P. Alt, and J. D. Neill. 2007. Papillomatous digital dermatitis spirochetes suppress the bovine macrophage innate immune response. Vet. Microbiol. $125: 256-264$ 